\title{
New Developments in the Pathophysiology and Management of Primary Immune Thrombocytopenia
}

\author{
Karina Althaus ${ }^{1,2}$ Christoph Faul ${ }^{3}$ Tamam Bakchoul ${ }^{1,2}$ \\ ${ }^{1}$ Transfusion Medicine, Medical Faculty of Tübingen, University \\ Hospital of Tübingen, Tübingen, Germany \\ ${ }^{2}$ Centre for Clinical Transfusion Medicine, University Hospital of \\ Tübingen, Tübingen, Germany \\ 3 Internal Medicine II, University Hospital of Tübingen, Tübingen, Germany \\ Address for correspondence Tamam Bakchoul, MD, University \\ Hospital of Tübingen, Otfried-Müller-Straße 4/1, 72076 Tübingen, \\ Germany (e-mail: tamam.bakchoul@med.uni-tuebingen.de). \\ Hamostaseologie 2021;41:275-282.
}

\begin{abstract}
Keywords

- platelet immunology

- immune thrombocytopenia

- autoantibodies

- autoimmune diseases

Immune thrombocytopenia (ITP) is an autoimmune disease that is characterized by a significant reduction in the number of circulating platelets and frequently associated with bleeding. Although the pathogenesis of ITP is still not completely elucidated, it is largely recognized that the low platelet count observed in ITP patients is due to multiple alterations of the immune system leading to increased platelet destruction as well as impaired thrombopoiesis. The clinical manifestations and patients' response to different treatments are very heterogeneous suggesting that ITP is a group of disorders sharing common characteristics, namely, loss of immune tolerance toward platelet (and megakaryocyte) antigens and dysfunctional primary hemostasis. Management of ITP is challenging and requires intensive communication between patients and caregivers. The decision to initiate treatment should be based on the platelet count level, age of the patient, bleeding manifestation, and other factors that influence the bleeding risk in individual patients. In this review, we present recent data on the mechanisms that lead to platelet destruction in ITP with a particular focus on current findings concerning alterations of thrombopoiesis. In addition, we give an insight into the efficacy and safety of current therapies and management of ITP bleeding emergencies.
\end{abstract}

\section{Introduction}

Primary immune thrombocytopenia (ITP) is an autoimmune bleeding disorder characterized by bleeding due to isolated thrombocytopenia with platelet count less than $100 \times 10^{9} /$ L. ${ }^{1-4}$ The incidence of ITP ranges between 3.3 and 3.9/100,000 per year in adults, and between 1.9 and $6.4 / 100,000$ per year in children. ${ }^{3,5}$ The exact mechanism of the immune repsonse toward own cells (autoimmunity) leading to TIP are incompletely understood, but includes an alteration of the balance between effectors and regulatory cells. ${ }^{6}$ This imbalance results in a breakdown of the immune tolerance causing increased platelet clearance and impaired thrombopoiesis. For a long time, it was thought that the low platelet count is solely caused by enhanced destruction of platelets opsonized by antiplatelet

received

July 8,2020

accepted after revision

November 15, 2020 antibodies. ${ }^{7-9}$ However, recent studies have shown that T-cell cytotoxicity and impaired megakaryopoiesis are additional pathomechanisms in ITP.

While a brief course with spontaneous remission is frequently observed in the majority of children with ITP, most adult patients display chronic ITP which can be associated with clinically significant bleeding, including hemorrhages in skin or mucous membranes such as petechiae, purpura, and rarely intracranial manifestations. ${ }^{10,11}$ Based on these clinical symptoms, the primary therapeutic aim in ITP is to reduce the risk of severe bleeding and not necessarily to increase platelet count. According to the International Working Group, ${ }^{2,12}$ newly diagnosed patients with ITP who are at low risk of bleeding can be safely managed with observation (wait and see strategy), while those with severe chronic

$\begin{array}{ll}\text { (c) 2020. Thieme. All rights reserved. } & \text { DOI https://doi.org/ } \\ \text { Georg Thieme Verlag KG, } & 10.1055 / a-1311-8264 . \\ \text { Rüdigerstraße 14, } & \text { ISSN 0720-9355. } \\ 70469 \text { Stuttgart, Germany } & \end{array}$


thrombocytopenia or at higher risk of bleeding require urgent treatment.

This review explores the mechanisms leading to platelet destruction in ITP with a particular focus on current findings concerning alterations of thrombopoiesis. In addition, we will address common questions about therapy for ITP, including when to treat/when not to treat, efficacy and safety of therapies, management of ITP bleeding emergencies, and unique treatment considerations.

\section{New Insights into the Pathophysiology of Immune Thrombocytopenia}

The loss of immunological tolerance to autoantigens expressed on patients' own platelets has been identified as one of the critical issues in the pathophysiology of ITP. In this context, several studies reported T-cell abnormalities with an imbalance in T helper (Th)1:Th2 ratio in ITP patients. ${ }^{13,14}$ Dysfunction of these cells is thought to be responsible for increased number and activity of cytotoxic $\mathrm{T}$ lymphocytes. This increased activity contributes directly to the increased platelet destruction as well as improved survival of B-cell. These B-cells with enhanced survival produce autoantibodies against platelet leading to accelerated platelet clearance. Upon binding of these autoantibodies, platelets were eliminated through phagocytosis, apoptosis, complement activation, and impairment of platelet production. ${ }^{15,16}$ While these Fc-mediated mechanisms seem to predominantly induce platelet destruction in the spleen, recent studies proposed new Fc-independent mechanisms. ${ }^{17-19}$ ITP autoantibodies were shown to induce glycan modification of platelet surface glycoproteins (GPs), which are recognized by Ashwell-Morell receptors, expressed on hepatocytes, leading to accelerated platelet clearance in the liver. ${ }^{20}$ In some patients, this may explain the ineffectiveness of splenectomy which represents the last ITP therapeutic option for refractory subjects. Interestingly, 2 years later, a retrospective study involving 61 ITP patients reported a correlation between platelets desialylation and a reduced response to first-line treatments corroborating the hypothesized Fc-independent mechanism. ${ }^{21,22}$ Another Fc-independent mechanism has been suggested by Quach et al who showed that nonresponding ITP patients often produce autoantibodies targeting the ligand-binding domain (LBD) of GPIb/IX. This specific binding can activate GPIb/IX by platelet receptor crosslinking, inducing unfolding of its mechanosensory domain and the consequent platelet destruction. ${ }^{23}$ Recently, we showed that patients with autoantibodies who can induce desialylation in platelet and megakaryocytes have more sever course of ITP. ${ }^{24}$ The use of sialidase inhibitor treatment in combination with other therapies might be a promising approach to increase platelet count in some patients who have failed previous therapies.

The platelet life cycle is regulated by the intrinsic apoptotic pathway similar to nucleated $B$-cells. Considering this, the contribution of ITP autoantibodies in inducing platelet apoptosis was investigated by several groups using well-defined apoptosis markers such as depolarization of the mitochondrial transmembrane potential, Bcl-2 family protein expres- sion, caspase- 3 and -9 activation, and phosphatidylserine exposure. ${ }^{25,26}$ Apoptosis in platelets from pediatric and adult patients was ameliorated by immunoglobulin infusion. ${ }^{27,28}$ Interestingly, in a recent study, apoptotic platelets were found in ITP patients expressing anti-GPIIb/IIIa and antiGPIb autoantibodies but not in those carrying anti-GPIa/IIa autoantibodies. $^{29}$ This suggests a possible preferential specificity of the autoantibodies in inducing platelets apoptosis. Although the exact mechanism of autoantibody-mediated platelet apoptosis is not completely known currently, these findings suggest a relevant contribution of the apoptotic pathway in the ITP pathogenesis, opening novel horizons for deeper investigations.

Autoantibody binding also results in suppression of megakaryocyte maturation and platelet formation. ${ }^{30,31}$ The antibody-mediated inhibition of platelet production was demonstrated by in vitro studies showing impaired megakaryocyte maturation and decreased platelet formation. ${ }^{32-34}$ An interesting open question is, however, the role of megakaryocyte apoptosis in the ITP pathophysiology. Controversial results were presented in several studies during the last few years. In fact, it has been reported that ITP plasma can reduce megakaryocyte apoptosis. ${ }^{35}$ In particular, after cultivation of human stem cells (HSCs) from healthy umbilical cord blood with ITP plasma, a decreased percentage of apoptotic cells, reduced expression of tumor necrosis factor-related apoptosis inducing ligand, and increased expression of the antiapoptotic protein $\mathrm{Bcl}$-xL have been observed in the differentiated megakaryocytes. $^{36}$ In contrast, an in vivo study published by Houwerzijl et al showed that megakaryocytes undergo apoptosis in the presence of autoantibodies displaying nuclear fragmentation, chromatin condensation, and activation of caspase 3, in biopsies of ITP patients, leading to phagocytosis of the polyploid cells by macrophages residing in the bone marrow. ${ }^{37}$ A more recent study showed increased megakaryocyte apoptosis in bone marrow samples of ITP patients. ${ }^{38}$

\section{Diagnosis}

The diagnosis of ITP is often based on the exclusion of other causes of thrombocytopenia. ${ }^{2,12,39}$ Diagnosis can be made in patients with platelet count less than $100,000 / \mu \mathrm{L}$ who lack findings that suggest another diagnosis in their history, physical examination, complete blood cell count, and blood smear. Identifying alternative causes of thrombocytopenia can, however, be difficult and requires comprehensive expertise in platelet disorders. Detection of a characteristic autoantibody proves the diagnosis of ITP. Although many guidelines consider further laboratory testings unnecessary, positive results obtained in GP-specific assays such as direct monoclonal Antibody-specific Immobilization of Platelet Antigen (MAIPA) or direct immunobead assay prove the diagnosis of ITP. ${ }^{40}$ However, due to the lack of a strong evidence for clinical advantage, current guidelines from the 2019 American Society of Hematology (2019 ASH) do not give a clear recommendation for antibody evaluation in ITP. ${ }^{4}$ Testing of the presence of platelet autoantibodies should be performed as part of the initial assessment, as a positive test 
result establishes a sound basis for further diagnostic procedures and treatment. Despite the excellent specificity of the test, a significant drawback of direct GP-specific tests is their low sensitivity, and a negative test result has no relevance. It is therefore useful to establish a diagnosis of (primarily) hyperdestructive thrombocytopenia early in the patient's assessment.

\section{Treatments}

\section{Active Bleeding}

Reported rates of severe bleeding vary depending on the population studied. A recent systematic review including 118 studies with 10,908 ITP patients revealed a rate of intracranial hemorrhage (ICH) of 1.0\% (95\% confidence interval [CI]: 0.7-1.3). Deaths due to bleeding are rare, and overall mortality among patients with ITP is only slightly higher than age- and sex-matched controls. ${ }^{41}$ The overall rate of non-ICH major bleeding was $15.0 \%$ (95\% CI: 4.1-17.1). A more recent study used a validated ITP bleeding assessment tool to measure bleeding in ITP. ${ }^{42}$ This study reported that $56 \%$ of ITP patients had severe bleeding at some point during their disease course, and $2 \%$ had $\mathrm{ICH}^{4}{ }^{43}$

The main aims of ITP treatment are to stop active bleeding and reduce the risk of future bleeding. Specific measures to stop bleeding should include, besides withdrawal of anticoagulant and antiplatelet agents, the administration of glucocorticoids, intravenous immunoglobulin (IVIG), and transfusion of platelet concentrate or all of these measures. However, data from randomized trials are still lacking, and the use of these treatments is supported generally by small observational studies. In addition, some limitations of these approaches should be taken into consideration. Platelet transfusions can help limit bleeding, but the effect is commonly transient, due to the rapid clearance by the autoantibodies. Thus, they should not be used alone but rather in combination with IVIG or/and glucocorticoids. IVIG raises the platelet count within 2 to 4 days in $80 \%$ of patients, but effects last only 1 to 2 weeks. Therefore, concomitant use of glucocorticoids with IVIG can be considered to achieve more sustained response than that with IVIG alone. ${ }^{44}$ In life-threatening situations, additional treatments may be required. Drugs that may be useful in patients with ITP to control minor bleeding are tranexamic acid (particularly for mucocutaneous bleeds) and contraception (menorrhagia). ${ }^{45,46}$ In life-threatening ITP bleeding emergencies, recombinant activated factor VII may be a useful supportive treatment.

\section{Bleeding Prophylaxis}

In asymptomatic thrombocytopenia patients and in those who have only mild mucocutaneous bleeding, a careful risk assessment of future bleeding and patient preferences should be taken into consideration in decision making for bleeding prophylaxis. However, the usefulness of current bleeding scores in clinical practice is limited by their complexity and lack of validation in large studies. ${ }^{42}$ From a clinical point of view and despite the lack of sufficient data from prospective studies, a platelet count of less than $30,000 / \mu \mathrm{L}$ and/or comorbidity is frequently used as a reliable cut-off for treatment in adults according to the 2019 ASH guidelines. ${ }^{4}$ However, other risk factors besides platelet count should be taken into account, such as age (e.g., $>65$ years), history of bleeding, concomitant use of anticoagulants and platelet inhibitors, renal or hepatic impairment, and the risk of trauma from daily activities. ${ }^{47,48}$ It is generally recommended that patients who are receiving anticoagulants or antiplatelet agents should receive treatment to maintain platelet count above $50,000 / \mu \mathrm{L}$.

Although the platelet count is an important marker for disease activity in ITP, the decision-making to initiate therapy should be individualized and take bleeding risk factors and patient preferences into account. Our suggested approach to first-line therapy in adults and children is summarized in -Table 1, as well as in - Fig. 1.

\section{Glucocorticoids}

Glucocorticoid treatment is the standard initial therapy for patients with ITP. Prednisone and dexamethasone are most commonly used agents. Prednisone is given 0.5 to $2 \mathrm{mg} / \mathrm{kg}$ orally per day for 1 to 2 weeks, with a gradual withdraw and discontinuation by 6 to 8 weeks. Dexamethasone is administrated as one or more cycles of $40 \mathrm{mg}$ orally once daily for 4 days, usually 4 weeks apart. A meta-analysis of randomized trials found that platelet counts were higher at 14 days in patients receiving dexamethasone compared with patients receiving prednisone, but overall responses at 6 months did not differ significantly. ${ }^{50}$ So, there is no clear advantage for dexamethasone over prednisone.

Although 60 to $80 \%$ of patients with ITP have an initial response to glucocorticoids, only 20 to $40 \%$ of adults have a sustained response after glucocorticoids are discontinued. ${ }^{51,52}$ Medical therapies for patients with ITP who do not have an initial response to glucocorticoids or who have recurrent decreases in platelet count after glucocorticoids are discontinued include thrombopoietin-receptor agonists (TPO-RAs) and immunomodulators. Importantly, corticosteroids should be withdrawn rapidly and discontinued in nonresponding patients to prevent toxicities associated with prolonged corticosteroid exposure, including weight gain and osteoporosis, but result in acute toxicities including cognitive impairments, hypertension, and hyperglycemia.

\section{Intravenous Immunoglobulin}

IVIG raises the platelet count more rapidly than corticosteroids. ${ }^{53}$ In a multicenter, randomized study of 122 adults with newly diagnosed ITP, IVIG was shown to be more effective at raising the platelet count by day 5 than corticosteroids ( 79 vs. $60 \%$ response rate). The guidelines from the ASH recommend that IVIG should be given initially as a single dose of $1 \mathrm{~g} / \mathrm{kg}$ and repeated in nonresponding patients. ${ }^{2}$ In fact, a randomized trial of 37 adults with ITP showed that a single IVIG dose of $1 \mathrm{~g} /$ $\mathrm{kg}$ is more likely to induce a platelet count response by day 4 compared with patients who received lower initial doses of $0.5 \mathrm{~g} / \mathrm{kg}$ (67 vs. $21 \%)^{44}$ indicating that an initial IVIG dose of $1 \mathrm{~g} / \mathrm{kg}$ is preferred for most patients with the possibility of repeating a second dose the next day. Common side effects of 
Table 1 Current therapies in adults and children with ITP according to the 2019 ASH guidelines 4

\begin{tabular}{|c|c|c|}
\hline & Adult & Children \\
\hline \multicolumn{3}{|c|}{ Therapy vs. observation } \\
\hline Observation & $\begin{array}{l}\text { Newly diagnosed ITP and a platelet count } \\
>30 \times 10^{9} / \mathrm{L} \text { who are asymptomatic or have minor } \\
\text { mucocutaneous bleeding }\end{array}$ & $\begin{array}{l}\text { Newly diagnosed ITP with no or minor bleeding } \\
\text { (recommendation with low evidence) }\end{array}$ \\
\hline Therapy & $\begin{array}{l}\text { Platelet count }<30 \times 10^{9} / \mathrm{L} \text { and/or additional } \\
\text { comorbidities, anticoagulant or antiplatelet med- } \\
\text { ications and/or upcoming procedures, and/or for } \\
\text { elderly patients ( }>60 \text { years old) }\end{array}$ & $\begin{array}{l}\text { Platelet count }<20 \times 10^{9} \text { and non-life-threaten- } \\
\text { ing mucosal bleeding and/or diminished health- } \\
\text { related quality of life }\end{array}$ \\
\hline \multicolumn{3}{|l|}{ Therapy with } \\
\hline Corticosteroids & $\begin{array}{l}\text { Prednisone }(0.5-2.0 \mathrm{mg} / \mathrm{kg} \text { per day) or dexa- } \\
\text { methasone ( } 40 \mathrm{mg} \text { per day for } 4 \text { days })\end{array}$ & $\begin{array}{l}\text { Prednisone ( } 2-4 \mathrm{mg} / \mathrm{kg} \text { per day; maximum, } \\
120 \mathrm{mg} \text { daily for } 5-7 \text { days) rather than dexa- } \\
\text { methasone }(0.6 \mathrm{mg} / \mathrm{kg} \text { per day; maximum, } 40 \mathrm{mg} \\
\text { per day for } 4 \text { days) }\end{array}$ \\
\hline IVIG & $\begin{array}{l}\text { Single dose }(1 \mathrm{~g} / \mathrm{kg}) \text { and repeated the following } \\
\text { day in nonresponding patients. For treatment of } \\
\text { acute bleeding or for rapid platelet count response } \\
\text { within } 12-24 \mathrm{~h}\end{array}$ & $\begin{array}{l}\text { IVIG is not recommended as first-line therapy for } \\
\text { children except in case of major bleeding }\end{array}$ \\
\hline Rituximab & $\begin{array}{l}\text { Rituximab is not recommended for first-line ther- } \\
\text { apy. Only if there is high evidence for remission, an } \\
\text { initial course of rituximab in combination with } \\
\text { corticosteroids may be preferred }\end{array}$ & Not for first-line treatment \\
\hline TPO-RAs & \multicolumn{2}{|c|}{$\begin{array}{l}\text { No first-line treatment. Observational studies may have evidence for increased remission in patients with } \\
\text { early use }\end{array}$} \\
\hline $\begin{array}{l}\text { Emergency } \\
\text { treatment }\end{array}$ & \multicolumn{2}{|c|}{$\begin{array}{l}\text { High-dose corticosteroids, IVIG, and platelet transfusions. Supportive treatments may include recombinant } \\
\text { factor VIla, tranexamic acid, and TPO-RAs }\end{array}$} \\
\hline
\end{tabular}

Abbreviations: ASH, American Society of Hematology; ITP, immune thrombocytopenia; IVIG, intravenous immunoglobulin; TPO-RA, thrombopoietin receptor agonist.

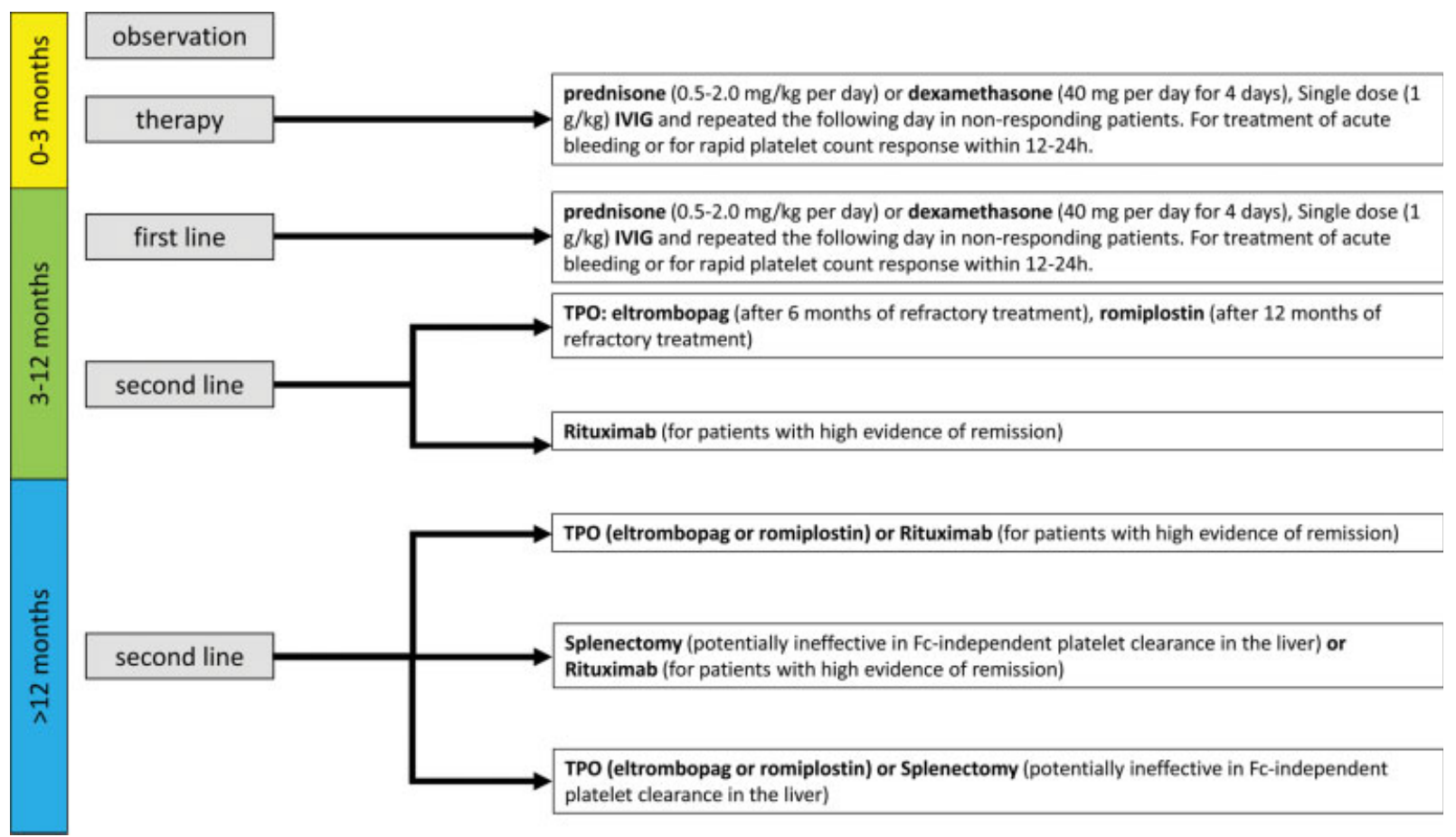

Fig. 1 Suggested algorithm to manage immune thrombocytopenia (ITP) in adults for first- and second-line therapy adapted from the guidelines of 2019 American Society of Hematology. ${ }^{4}$ Therapeutic options differ considering the stage of disease. During the first 3 months after onset of ITP, observation rather than therapy is indicated. In second-line therapy, personalized medicine should be chosen taking comorbidities, compliance, patient values, and preferences into consideration. Contraindications, potential adverse effects, and ineffectiveness of should be carefully evaluated. ${ }^{20,49}$ 
IVIG include headache, aseptic meningitis, acute kidney injury, and hemolysis from passive transfer of anti-A and anti-B hemagglutinins in patients with non-O blood group. ${ }^{54-57}$ Moreover, IVIG has been suggested to be associated with an increased risk of thrombosis. ${ }^{58}$ However, a recent systematic review of 31 randomized trials did not demonstrate an increased risk of thromboembolism due to IVIG (odds ratio [OR]: 1.10 ; 95\% CI: 0.44-2.88). ${ }^{59-61}$

\section{Anti-Rh(D) Immunoglobulin}

Anti-RhD Ig is thought to bind and occupy Fc receptors in the reticuloendothelial system with antibody-coated $\mathrm{Rh}(\mathrm{D})$-positive red blood cells, thus preventing antibody-coated platelets from being destroyed. ${ }^{62}$ Anti-RhD Ig is usually given intravenously for patients with $\mathrm{Rh}(\mathrm{D})$-positive blood type with an intact spleen as single dose of 50 to $75 \mu \mathrm{g} / \mathrm{kg}$. A safe subcutaneous administration in small children or patients is also described in the literature. ${ }^{63}$ Side effects include mild infusion reactions such as headache, nausea, chills, fever, and mild to moderate hemolysis. ${ }^{64}$ However, life-threatening episodes of severe intravascular hemolysis associated with anti-Rh Ig administration have been reported. ${ }^{65,66}$ It is noteworthy to mention that, in some countries, anti-D for ITP treatment is not approved as a licensed treatment for ITP.

\section{Thrombopoietin-Receptor Agonists}

Eltrombopag and romiplostim are TPO-RAs for patients with ITP that is refractory to other treatment and with disease lasting more than 6 months (eltrombopag) or 12 months (romiplostim). ${ }^{67}$ In randomized, placebo-controlled trials of each of these agents involving patients with chronic ITP in whom at least one previous therapy has failed, 70 to $95 \%$ of patients had an increased platelet count with initial treatment and 40 to $60 \%$ had durable responses with ongoing treatment. $^{68,69}$

Eltrombopag is administered as a daily tablet, whereas romiplostim is administered in weekly subcutaneous injections. In Germany, TPO-RAs received approval for treatment even before splenectomy. The choice between the two agents is guided by the preferred form of administration and anticipated adherence. Interestingly, some observational data suggest that if one agent is ineffective, switching to the other results in a platelet response in up to $50 \%$ of patients. $^{70,71}$

An initial response to TPO-RAs usually occurs within 1 to 2 weeks. Once a response is achieved, ongoing treatment is required to maintain effect. However, retrospective and prospective cohort studies have shown that 10 to $30 \%$ of patients can discontinue treatment after receiving TPO-RAs for many months or years, and the disease remains in remission, although late relapses may occur. ${ }^{72,73}$ Although some patients seem to have a prolonged/complete remission after pausing TPO, no prognostic marker is currently available to identify such patients.

The main safety concern is an increased risk of venous thromboembolism. ${ }^{74}$ In extension studies of both agents, thromboembolism developed in $6 \%$ of patients during a median follow-up of 2 years. ${ }^{75,76}$
A new oral TPO-RA is avatrombopag, which, unlike eltrombopag, can be administered without dietary restrictions. The phase 3 clinical trials showed a longer median number of weeks with platelet count of $50,000 / \mu \mathrm{L}$ or higher during the first 26 weeks in patients who received avatrombopag than in those who received placebo. ${ }^{77}$

\section{Immunomodulators}

Rituximab is widely used for the immunomodulation in patients with ITP, although it is not approved for this indication. In a meta-analysis including five randomized studies, significantly higher incidence of complete response at 6 months was observed with rituximab compared with glucocorticoids or placebo. ${ }^{78}$ of note, the response to rituximab is typically observed within 1 to 8 weeks. The main advantage of rituximab over other immunomodulators is the sustained platelet responses that last more than 2 years in $50 \%$ of patients who have a response. ${ }^{79,80}$ An increase in minor infections has been reported with rituximab. However, major complications such as progressive multifocal leukoencephalopathy seem to be rare. ${ }^{81}$ Taken together, due to the lower efficacy and higher complications compared with TPO-RAs, ${ }^{82}$ rituximab should be avoided as firstline therapy and used only if there is high evidence for remission. ${ }^{4}$

Fostamatinib is an oral tyrosine kinase (Syk) inhibitor that can be used to treat patients with ITP in whom one previous therapy has failed. Recently, fostamatinib was shown to induce a response within 12 weeks in $43 \%$ compared with $14 \%$ of those receiving placebo. In addition, a sustained platelet count $\geq 50,000 / \mu \mathrm{L}$ for up to 24 weeks was observed in $18 \%$ of refractory ITP patients compared with $2 \%$ of those receiving placebo. ${ }^{83}$

Hydroxychloroquine is described as a steroid-sparing agent that can be helpful for treatment purposes. Especially in secondary ITP, it might be an option in patients with systemic lupus erythematodes. However, there is limited information on this and further studies are needed to conclude about efficacy of this treatment. ${ }^{84}$

Dapsone, danazol, and several immunosuppressive agents are also used in patients with ITP. However, data to support their use are largely limited to retrospective observational studies that suggest that 30 to $60 \%$ of patients have a response.

Tranexamic acid is described in two studies as highly effective in controlling menorrhagia and acute bleeding in female patients with ITP and should be taken into account in the treatment of female patients with chronic ITP. ${ }^{45,46}$

\section{Splenectomy}

Splenectomy remains the most effective therapy for ITP inducing long-lasting remissions in 60 to $70 \%$ of patients. ${ }^{85}$ To reveal the site of platelet clearance is a promising predictor of therapy response, but the indium-labeled autologous platelet scanning is technically challenging and not widely available all over the world. ${ }^{86}$ Knowledge of desialylation capacity of the antibody might also helpful to detect Fcindependent clearance of platelets in the liver. ${ }^{20}$ Nevertheless, the potential complications of splenectomy, and the inability to predict responsiveness, is usually limited to 
chronic ITP patients who do not have a response to standard medical therapies. ${ }^{86,87}$ Short-term risks of splenectomy include operative and postoperative complications, including venous thromboembolism and sepsis. Laparoscopic splenectomy is associated with lower postoperative mortality and morbidity and a shorter recovery time than open splenectomy. ${ }^{85,88}$ Moreover, the immediate as well as the persistent risk of venous thromboembolism has been shown to be higher among patients with ITP who have undergone splenectomy as compared with those who have not undergone splenectomy. ${ }^{89,90}$ Besides thromboembolic complications, splenectomy is associated with an increased risk of infection with encapsulated bacteria; vascular complications, such as coronary artery disease and stroke; and chronic thromboembolic pulmonary hypertension. Thus, splenectomy is generally not recommended in frail elderly patients because of increased surgical complications in this patient population. More importantly, splenectomy should be postponed in the first 12 months.

\section{Conclusions}

ITP is a complex and multifactorial disease. Currently, there is a general consensus that the pathophysiology of ITP is caused by abnormal function of regulatory B- and T-cells leading to proliferation of platelet-specific plasma and cytotoxic cells, respectively. While the latter is responsible for a direct destruction of platelet as well as megakaryocyte in ITP, IgG autoantibodies can induce thrombocytopenia in ITP by several Fc-domain dependent and independent mechanisms including platelet phagocytosis, complement activation, apoptosis, cell lysis, and inhibition of proplatelet production. The urgent management to treat active, clinically relevant bleeding in ITP patients should include discontinuation of any anticoagulation or platelet-function inhibitors if taken, platelet transfusions, and IVIG and steroids. In acute bleeding, IVIG and corticosteroids might be more effective than platelet transfusions alone. Since a cure for ITP is currently still missing, the aim of treating ITP patients with significant bleeding tendency should be to stop bleeding (usually reaching a stable platelet count above $30,000 / \mu \mathrm{L}$ ). If initial treatment with IVIG and steroids was not successful in inducing remission or if relapse occurred while withdrawing steroids, TPO-RA is recommended. Rituximab and splenectomy can be considered as alternative therapeutic strategies in refractory ITP patients.

\section{Conflicts of Interest}

K.A. received research grant from the German Red Cross. T. B. reports receiving honorarium for a scientific talk from Aspen Germany, CSL Behring, and Stago GmbH German and research grants from the German Society of Research, the German Society for Transfusion Medicine, and German Red Cross.

\section{Acknowledgment}

This work was supported by grant from the TÜFF-Gleichstellungsförderung to K.A. (2563-0-0).

\section{References}

1 Provan D, Stasi R, Newland AC, et al. International consensus report on the investigation and management of primary immune thrombocytopenia. Blood 2010;115(02):168-186

2 Neunert C, Lim W, Crowther M, Cohen A, Solberg L Jr, Crowther MAAmerican Society of Hematology. The American Society of Hematology 2011 evidence-based practice guideline for immune thrombocytopenia. Blood 2011;117(16):4190-4207

3 Moulis G, Palmaro A, Montastruc JL, Godeau B, Lapeyre-Mestre M, Sailler L. Epidemiology of incident immune thrombocytopenia: a nationwide population-based study in France. Blood 2014;124 (22):3308-3315

4 Neunert C, Terrell DR, Arnold DM, et al. American Society of Hematology 2019 guidelines for immune thrombocytopenia. Blood Adv 2019;3(23):3829-3866

5 Bennett CM, Neunert C, Grace RF, et al. Predictors of remission in children with newly diagnosed immune thrombocytopenia: data from the Intercontinental Cooperative ITP Study Group Registry II participants. Pediatr Blood Cancer 2018;65(01):. Doi: 10.1002/ pbc.26736

6 McKenzie CG, Guo L, Freedman J, Semple JW. Cellular immune dysfunction in immune thrombocytopenia (ITP). Br J Haematol 2013;163(01):10-23

7 Shulman NR, Marder VJ, Weinrach RS. Similarities between known antiplatelet antibodies and the factor responsible for thrombocytopenia in idiopathic purpura. Physiologic, serologic and isotopic studies. Ann N Y Acad Sci 1965;124(02): 499-542

8 Ku FC, Tsai CR, Der Wang J, Wang CH, Chang TK, Hwang WL. Stromal-derived factor-1 gene variations in pediatric patients with primary immune thrombocytopenia. Eur J Haematol 2013; 90(01):25-30

9 Rank A, Weigert O, Ostermann H. Management of chronic immune thrombocytopenic purpura: targeting insufficient megakaryopoiesis as a novel therapeutic principle. Biologics 2010; 4:139-145

10 Cines DB, Liebman HA. The immune thrombocytopenia syndrome: a disorder of diverse pathogenesis and clinical presentation. Hematol Oncol Clin North Am 2009;23(06):1155-1161

11 D'Orazio JA, Neely J, Farhoudi N. ITP in children: pathophysiology and current treatment approaches. J Pediatr Hematol Oncol 2013; 35(01):1-13

12 Provan D, Arnold DM, Bussel JB, et al. Updated international consensus report on the investigation and management of primary immune thrombocytopenia. Blood Adv 2019;3(22): 3780-3817

13 Zhao Z, Yang L, Yang G, et al. Contributions of T lymphocyte abnormalities to therapeutic outcomes in newly diagnosed patients with immune thrombocytopenia. PLoS One 2015;10 (05):e0126601

14 Ji X, Zhang L, Peng J, Hou M. T cell immune abnormalities in immune thrombocytopenia. J Hematol Oncol 2014;7:72

15 Zhang F, Chu X, Wang L, et al. Cell-mediated lysis of autologous platelets in chronic idiopathic thrombocytopenic purpura. Eur J Haematol 2006;76(05):427-431

16 Zhao C, Li X, Zhang F, Wang L, Peng J, Hou M. Increased cytotoxic Tlymphocyte-mediated cytotoxicity predominant in patients with idiopathic thrombocytopenic purpura without platelet autoantibodies. Haematologica 2008;93(09):1428-1430

17 Nieswandt B, Bergmeier W, Rackebrandt K, Gessner JE, Zirngibl H. Identification of critical antigen-specific mechanisms in the development of immune thrombocytopenic purpura in mice. Blood 2000;96(07):2520-2527

18 Nieswandt B, Bergmeier W, Schulte V, Rackebrandt K, Gessner JE, Zirngibl $\mathrm{H}$. Expression and function of the mouse collagen receptor glycoprotein VI is strictly dependent on its association with the FcRgamma chain. J Biol Chem 2000;275(31): 23998-24002 
19 Webster ML, Sayeh E, Crow M, et al. Relative efficacy of intravenous immunoglobulin $\mathrm{G}$ in ameliorating thrombocytopenia induced by antiplatelet GPIIbIIIa versus GPIbalpha antibodies. Blood 2006;108(03):943-946

$20 \mathrm{Li}$ J, van der Wal DE, Zhu G, et al. Desialylation is a mechanism of Fc-independent platelet clearance and a therapeutic target in immune thrombocytopenia. Nat Commun 2015;6:7737

21 Tao L, Zeng Q, Li J, et al. Platelet desialylation correlates with efficacy of first-line therapies for immune thrombocytopenia. J Hematol Oncol 2017;10(01):46

22 Li J, Sullivan JA, Ni H. Pathophysiology of immune thrombocytopenia. Curr Opin Hematol 2018;25(05):373-381

23 Quach ME, Dragovich MA, Chen W, et al. Fc-independent immune thrombocytopenia via mechanomolecular signaling in platelets. Blood 2018;131(07):787-796

24 Marini I, Zlamal J, Faul C, et al. Autoantibody-mediated desialylation impairs human thrombopoiesis and platelet life span. Haematologica 2019; (epub ahead of print). Doi: 10.3324/haematol.2019.236117

25 Mason KD, Carpinelli MR, Fletcher JI, et al. Programmed anuclear cell death delimits platelet life span. Cell 2007;128(06): 1173-1186

26 van der Wal DE, Gitz E, Du VX, et al. Arachidonic acid depletion extends survival of cold-stored platelets by interfering with the [glycoprotein Ib $\alpha-14-3-3 \zeta$ ] association. Haematologica 2012;97 (10):1514-1522

27 Alvarez Román MT, Fernández Bello I, Arias-Salgado EG, et al. Effects of thrombopoietin receptor agonists on procoagulant state in patients with immune thrombocytopenia. Thromb Haemost 2014;112(01):65-72

28 Winkler J, Kroiss S, Rand ML, et al. Platelet apoptosis in paediatric immune thrombocytopenia is ameliorated by intravenous immunoglobulin. Br J Haematol 2012;156(04):508-515

29 Goette NP, Glembotsky AC, Lev PR, et al. Platelet apoptosis in adult immune thrombocytopenia: insights into the mechanism of damage triggered by auto-antibodies. PLoS One 2016;11(08): e0160563

30 McMillan R, Luiken GA, Levy R, Yelenosky R, Longmire RL. Antibody against megakaryocytes in idiopathic thrombocytopenic purpura. JAMA 1978;239(23):2460-2462

31 Takahashi R, Sekine N, Nakatake T. Influence of monoclonal antiplatelet glycoprotein antibodies on in vitro human megakaryocyte colony formation and proplatelet formation. Blood 1999; 93(06):1951-1958

32 Chang M, Nakagawa PA, Williams SA, et al. Immune thrombocytopenic purpura (ITP) plasma and purified ITP monoclonal autoantibodies inhibit megakaryocytopoiesis in vitro. Blood 2003;102 (03):887-895

33 McMillan R, Wang L, Tomer A, Nichol J, Pistillo J. Suppression of in vitro megakaryocyte production by antiplatelet autoantibodies from adult patients with chronic ITP. Blood 2004;103(04):1364-1369

34 Iraqi M, Perdomo J, Yan F, Choi PY, Chong BH. Immune thrombocytopenia: antiplatelet autoantibodies inhibit proplatelet formation by megakaryocytes and impair platelet production in vitro. Haematologica 2015;100(05):623-632

35 Yang L, Wang L, Zhao CH, et al. Contributions of TRAIL-mediated megakaryocyte apoptosis to impaired megakaryocyte and platelet production in immune thrombocytopenia. Blood 2010;116 (20):4307-4316

36 Radley JM, Haller CJ. Fate of senescent megakaryocytes in the bone marrow. Br J Haematol 1983;53(02):277-287

37 Houwerzijl EJ, Blom NR, van der Want JJ, et al. Ultrastructural study shows morphologic features of apoptosis and para-apoptosis in megakaryocytes from patients with idiopathic thrombocytopenic purpura. Blood 2004;103(02):500-506

38 Vrbensky JR, Nazy I, Toltl LJ, et al. Megakaryocyte apoptosis in immune thrombocytopenia. Platelets 2018;29(07):729-732
39 Cooper N. State of the art - how I manage immune thrombocytopenia. Br J Haematol 2017;177(01):39-54

40 Kiefel V, Freitag E, Kroll H, Santoso S, Mueller-Eckhardt C. Platelet autoantibodies (IgG, IgM, IgA) against glycoproteins IIb/IIIa and Ib/IX in patients with thrombocytopenia. Ann Hematol 1996;72 (04):280-285

41 Portielje JE, Westendorp RG, Kluin-Nelemans HC, Brand A. Morbidity and mortality in adults with idiopathic thrombocytopenic purpura. Blood 2001;97(09):2549-2554

42 Page LK, Psaila B, Provan D, et al. The immune thrombocytopenic purpura (ITP) bleeding score: assessment of bleeding in patients with ITP. Br J Haematol 2007;138(02):245-248

43 Arnold DM, Nazy I, Clare R, et al. Misdiagnosis of primary immune thrombocytopenia and frequency of bleeding: lessons from the McMaster ITP Registry. Blood Adv 2017;1(25):2414-2420

44 Godeau B, Chevret S, Varet B, et al;French ATIP Study Group. Intravenous immunoglobulin or high-dose methylprednisolone, with or without oral prednisone, for adults with untreated severe autoimmune thrombocytopenic purpura: a randomised, multicentre trial. Lancet 2002;359(9300):23-29

45 Mayer B, Salama A. Successful treatment of bleeding with tranexamic acid in a series of 12 patients with immune thrombocytopenia. Vox Sang 2017;112(08):767-772

46 Bartholomew JR, Salgia R, Bell WR. Control of bleeding in patients with immune and nonimmune thrombocytopenia with aminocaproic acid. Arch Intern Med 1989;149(09):1959-1961

47 Adelborg K, Kristensen NR, Nørgaard M, et al. Cardiovascular and bleeding outcomes in a population-based cohort of patients with chronic immune thrombocytopenia. J Thromb Haemost 2019;17 (06):912-924

48 Piel-Julian ML, Mahévas M, Germain J, et al;CARMEN Investigators Group. Risk factors for bleeding, including platelet count threshold, in newly diagnosed immune thrombocytopenia adults. J Thromb Haemost 2018;16(09):1830-1842

49 Marini I, Bakchoul T. Pathophysiology of autoimmune thrombocytopenia: current insight with a focus on thrombopoiesis. Hamostaseologie 2019;39(03):227-237

50 Mithoowani S, Gregory-Miller K, Goy J, et al. High-dose dexamethasone compared with prednisone for previously untreated primary immune thrombocytopenia: a systematic review and meta-analysis. Lancet Haematol 2016;3(10):e489-e496

51 Frederiksen $\mathrm{H}$, Ghanima W. Response of first line treatment with corticosteroids in a population-based cohort of adults with primary immune thrombocytopenia. Eur J Intern Med 2017;37:e23-e25

52 Cheng Y, Wong RS, Soo YO, et al. Initial treatment of immune thrombocytopenic purpura with high-dose dexamethasone. $\mathrm{N}$ Engl J Med 2003;349(09):831-836

53 Beck CE, Nathan PC, Parkin PC, Blanchette VS, Macarthur C. Corticosteroids versus intravenous immune globulin for the treatment of acute immune thrombocytopenic purpura in children: a systematic review and meta-analysis of randomized controlled trials. J Pediatr 2005;147(04):521-527

54 Sekul EA, Cupler EJ, Dalakas MC. Aseptic meningitis associated with high-dose intravenous immunoglobulin therapy: frequency and risk factors. Ann Intern Med 1994;121(04):259-262

55 Ahsan N. Intravenous immunoglobulin induced-nephropathy: a complication of IVIG therapy. J Nephrol 1998;11(03):157-161

56 Donga PZ, Bilir SP, Little G, Babinchak T, Munakata J. Comparative treatment-related adverse event cost burden in immune thrombocytopenic purpura. J Med Econ 2017;20(11):1200-1206

57 Padmore RF. Hemolysis upon intravenous immunoglobulin transfusion. Transfus Apheresis Sci 2012;46(01):93-96

58 Miltiadous O, Hou M, Bussel JB. Identifying and treating refractory ITP: difficulty in diagnosis and role of combination treatment. Blood 2020;135(07):472-490

59 Ammann EM, Haskins CB, Fillman KM, et al. Intravenous immune globulin and thromboembolic adverse events: a systematic 
review and meta-analysis of RCTs. Am J Hematol 2016;91(06): 594-605

60 Ammann EM, Jones MP, Link BK, et al. Intravenous immune globulin and thromboembolic adverse events in patients with hematologic malignancy. Blood 2016;127(02):200-207

61 Daniel GW, Menis M, Sridhar G, et al. Immune globulins and thrombotic adverse events as recorded in a large administrative database in 2008 through 2010. Transfusion 2012;52(10):2113-2121

62 Bussel JB, Graziano JN, Kimberly RP, Pahwa S, Aledort LM. Intravenous anti-D treatment of immune thrombocytopenic purpura: analysis of efficacy, toxicity, and mechanism of effect. Blood 1991; 77(09):1884-1893

63 Meyer O, Kiesewetter H, Hermsen M, et al. Replacement of intravenous administration of anti-D by subcutaneous administration in patients with autoimmune thrombocytopenia. Pediatr Blood Cancer 2006;47(5, Suppl):721-722

64 Scaradavou A, Woo B, Woloski BM, et al. Intravenous anti-D treatment of immune thrombocytopenic purpura: experience in 272 patients. Blood 1997;89(08):2689-2700

65 Gaines AR. Disseminated intravascular coagulation associated with acute hemoglobinemia or hemoglobinuria following $\mathrm{Rh}(0)$ (D) immune globulin intravenous administration for immune thrombocytopenic purpura. Blood 2005;106(05):1532-1537

66 Tarantino MD, Bussel JB, Cines DB, et al. A closer look at intravascular hemolysis (IVH) following intravenous anti-D for immune thrombocytopenic purpura (ITP). Blood 2007;109(12):5527, author reply 5528

67 Neunert CE. Thrombopoietin receptor agonist use for immune thrombocytopaenia. Hamostaseologie 2019;39(03):272-278

68 Kuter DJ, Bussel JB, Lyons RM, et al. Efficacy of romiplostim in patients with chronic immune thrombocytopenic purpura: a double-blind randomised controlled trial. Lancet 2008;371 (9610):395-403

69 Cheng G, Saleh MN, Marcher C, et al. Eltrombopag for management of chronic immune thrombocytopenia (RAISE): a 6-month, randomised, phase 3 study. Lancet 2011;377(9763):393-402

70 Khellaf M, Viallard JF, Hamidou M, et al. A retrospective pilot evaluation of switching thrombopoietic receptor-agonists in immune thrombocytopenia. Haematologica 2013;98(06):881-887

71 González-Porras JR, Mingot-Castellano ME, Andrade MM, et al. Use of eltrombopag after romiplostim in primary immune thrombocytopenia. Br J Haematol 2015;169(01):111-116

72 González-López TJ, Pascual C, Álvarez-Román MT, et al. Successful discontinuation of eltrombopag after complete remission in patients with primary immune thrombocytopenia. Am J Hematol 2015;90(03):E40-E43

73 Newland A, Godeau B, Priego V, et al. Remission and platelet responses with romiplostim in primary immune thrombocytopenia: final results from a phase 2 study. Br J Haematol 2016;172 (02):262-273

74 Rodeghiero F. Is ITP a thrombophilic disorder? Am J Hematol 2016;91(01):39-45

75 Wong RSM, Saleh MN, Khelif A, et al. Safety and efficacy of longterm treatment of chronic/persistent ITP with eltrombopag: final results of the EXTEND study. Blood 2017;130(23):2527-2536
76 Kuter DJ, Bussel JB, Newland A, et al. Long-term treatment with romiplostim in patients with chronic immune thrombocytopenia: safety and efficacy. Br J Haematol 2013;161(03):411-423

77 Jurczak W, Chojnowski K, Mayer J, et al. Phase 3 randomised study of avatrombopag, a novel thrombopoietin receptor agonist for the treatment of chronic immune thrombocytopenia. Br J Haematol 2018;183(03):479-490

78 Chugh S, Darvish-Kazem S, Lim W, et al. Rituximab plus standard of care for treatment of primary immune thrombocytopenia: a systematic review and meta-analysis. Lancet Haematol 2015;2 (02):e75-e81

79 Patel VL, Mahévas M, Lee SY, et al. Outcomes 5 years after response to rituximab therapy in children and adults with immune thrombocytopenia. Blood 2012;119(25):5989-5995

80 Ghanima W, Khelif A, Waage A, et al;RITP Study Group. Rituximab as second-line treatment for adult immune thrombocytopenia (the RITP trial): a multicentre, randomised, double-blind, placebo-controlled trial. Lancet 2015;385(9978):1653-1661

81 Khellaf M, Charles-Nelson A, Fain O, et al. Safety and efficacy of rituximab in adult immune thrombocytopenia: results from a prospective registry including 248 patients. Blood 2014;124(22): 3228-3236

82 Puavilai T, Thadanipon K, Rattanasiri S, et al. Treatment efficacy for adult persistent immune thrombocytopenia: a systematic review and network meta-analysis. Br J Haematol 2020;188 (03):450-459

83 Bussel J, Arnold DM, Grossbard E, et al. Fostamatinib for the treatment of adult persistent and chronic immune thrombocytopenia: results of two phase 3, randomized, placebo-controlled trials. Am J Hematol 2018;93(07):921-930

84 Mohammadpour F, Kargar M, Hadjibabaie M. The role of hydroxychloroquine as a steroid-sparing agent in the treatment of immune thrombocytopenia: a review of the literature. J Res Pharm Pract 2018;7(01):4-12

85 Kojouri K, Vesely SK, Terrell DR, George JN. Splenectomy for adult patients with idiopathic thrombocytopenic purpura: a systematic review to assess long-term platelet count responses, prediction of response, and surgical complications. Blood 2004;104(09):2623-2634

86 Chaturvedi S, Arnold DM, McCrae KR. Splenectomy for immune thrombocytopenia: down but not out. Blood 2018;131(11): 1172-1182

87 Matzdorff A, Meyer O, Ostermann H, et al. Immune thrombocytopenia - current diagnostics and therapy: recommendations of a joint working group of DGHO, ÖGHO, SGH, GPOH, and DGTI. Oncol Res Treat 2018;41(Suppl 5):1-30

$88 \mathrm{Qu} \mathrm{Y,} \mathrm{Xu} \mathrm{J,} \mathrm{Jiao} \mathrm{C,} \mathrm{Cheng} \mathrm{Z,} \mathrm{Ren} \mathrm{S.} \mathrm{Long-term} \mathrm{outcomes} \mathrm{of}$ laparoscopic splenectomy versus open splenectomy for idiopathic thrombocytopenic purpura. Int Surg 2014;99(03):286-290

89 Nørgaard M, Cetin K, Maegbaek ML, et al. Risk of arterial thrombotic and venous thromboembolic events in patients with primary chronic immune thrombocytopenia: a Scandinavian populationbased cohort study. Br J Haematol 2016;174(04):639-642

90 Boyle S, White RH, Brunson A, Wun T. Splenectomy and the incidence of venous thromboembolism and sepsis in patients with immune thrombocytopenia. Blood 2013;121(23):4782-4790 